\title{
Metacognitive Strategy and College English listening Teaching for Students Upgraded from Junior Colleges to Universities
}

\author{
Wei Liu \\ School of Foreign Languages, Dalian Jiaotong University, Dalian, 116028, China
}

\begin{abstract}
Keywords: College English of students upgraded from junior colleges to universities. Listening teaching. Metacognitive strategy
\end{abstract}

\begin{abstract}
Since college English teaching that is set for students upgraded from junior colleges to universities has short period and heavy tasks, its current situations are not optimistic. Especially, its listening teaching has much difficulty. Thus, how to help students break away from time-consuming and inefficient English learning and solve problems according to practical situations is a challenge that teachers face with. By analyzing causes for low listening level of students upgraded from junior colleges to universities, this thesis introduces metacognitive strategy to listening teaching and helps students cultivate metacognitive consciousness to improve listening ability of students upgraded from junior colleges to universities effectively.
\end{abstract}

\section{Introduction}

As Chinese economy rises rapidly, talent market proposes higher requirements for people's cultivation and an increasing number of people have chances to accept higher education [1]. Since education for students upgraded from junior colleges to universities is a special level of our higher education, its teaching has particularity. Upgrade of education background brings both hopes and pressure to students upgraded from junior colleges to universities.

\section{Current situations of English listening level of students upgraded from junior colleges to universities}

Generally, coherence and systematicness of study of students upgraded from junior colleges to universities are inferior to that of undergraduate students because some of them return to campus after having worked for several years and some of them have just finished their study at vocational schools. Besides, there is huge difference in such students' English level. Among 80 students upgraded from junior colleges to universities in Grade 2011 of a university at Dalian, where the author works, 1 student has passed CET-6 test before attending the school and 18 students have passed CET-4. However, the other 41 students have different situations. In detail, some students' knowledge belongs to entry level and some student can achieve CET-4 level by profound learning. Overall, such students' English level is low and the phenomenon that their listening ability is low is quite prominent. For students upgraded from junior colleges to universities, length of their schooling is two years. Usually, universities only establish one-year English lessons. How to improve students' listening level within a short period effectively is a huge challenge that all English teachers face with. Students' phonetic appearance is not good and lack systematic learning and training about pronunciation and intonation, which leads to the situation that have difficulty in audition and tonal discrimination. In addition, they do not have a correct habit of reading aloud but own poor language sense and fail to finish pronunciation and intonation correctly. Besides, they have lacked chances to communicate with others for a long time, so they are only used to reading in written form, which leads to low sensitivity to mutual convention between visual sense and auditory sense. Additionally, their context consciousness and ability of auditory comprehension are poor so that they usually make a deliberate misinterpretation out of context. Meanwhile, some students' spelling ability is so low that their spelling mistakes can be found everywhere and their word retention and basic skill are not sturdy. In compound dictation, obvious grammatical mistakes appear occasionally [2]. 


\section{Causes for poor listening ability of students upgraded from junior colleges to universities}

The author carried out a questionnaire for students upgraded from junior colleges to universities in Grade 2011 of a university in Dalian, where he works. The questionnaire involved 33 male students and 47 female students, and was divided into two parts. The first part focused on students' subjective description about their listening level. The second part centered on sorting surveys, where students were asked to analyze factors hindering improvement in their listening level and sort options that the author provided according to their significance in the order A-H. As a result, it is found that only three students are satisfied with their listening level. Causes for low listening level of students upgraded from junior colleges to universities are shown as follows successively.

a). Poor English learning atmosphere at junior colleges. A number of students fear English and most students only focus on A-level English examination during their study at junior colleges. However, the A-level English examination has low requirements for students' listening ability. Thus, students can pass it easily. In addition, English examinations for students' entrance to universities from junior colleges only test students' reading and writing ability, so the vigor that students input into listening is much less than that they input into reading and writing.

b). Incorrect pronunciation. Since students have few chances to practice listening, their phonetic appearance is affected naturally. As a result, most of students upgraded from junior colleges to universities do not dare to open their mouth but are afraid of making mistakes and jested by others. The higher the degree to which they are afraid of making mistakes, the more mistakes they will make; the more mistakes they make, the more afraid they will be. In consequence, a vicious circle is formed. Common phonetic phenomena like incorrect pronunciation, failure to adapt to authentic manner of pronunciation, un-accustomedness about coherent reading, assimilation of weak pronunciation and lost plosives directly make students fail to connect pronunciation with words and cannot figure out words they have learned when they hear standard and authentic pronunciation even if their reserves of words are abundant.

c). Students fail to think in English but translate English into Chinese in the process of listening. Since it is time-consuming to translate English into Chinese, it will cause low reaction speed for brain.

d). Poor ability of logical thinking and insufficient predictive ability. Ability of logical thinking and predictive ability are related to factors like knowledge and experience of people, and can be improved by hard study and training in our life.

e). Psychological causes. Since students have insufficient confidence in themselves, they generate negative emotions in listening practice, for instance, overstress, and even their brain becomes empty suddenly so that they cannot understand content that they can comprehend under a relaxing state. Actually, learning motivation of most students upgraded from junior colleges to universities is explicit. Subjectively, they want to learn English well but they encounter the phenomenon that the more the learning they carry out, the more the difficulty they will suffer; the more the difficulty they suffer, they more boring and the more afraid they will be. They lack patience and perseverance. Negative psychological reactions like tension, anxiety and fear will make their brain process information slowly and woodenly and even forget information when students do listening comprehension.

f). Training content is too difficult, methods and duration are inappropriate and students are not taught according to their aptitude. Additionally, students are anxious for success, which is also an important factor affecting improvement in listening ability.

\section{Metacognitive concept and listening comprehension}

As cognitive psychology develops, people have new comprehension of essence of the process of listening comprehension. As a result, listening comprehension is not regarded as a passive and acceptance process any more [3]. According to theories of Anderson a cognitive psychologist, the process of listening comprehension can be divided into three interdependent stages, i.e., perception, 
analysis and application. At the stage of perception, sounds are converted into representation of words and expression; at the stage of analysis, representation of words and expression is converted into representation of meaning; at the stage of application, people making comprehension apply meanings of information [4]. Thus, it is obvious that the process of listening comprehension is a process in which meanings are constructed actively and application of strategies has decisive effect on screening, processing, memory, storage and extraction of information. To practice listening well, it is essential to consider application of strategies to teaching in addition to carrying out learning and consolidation of basic language knowledge. Strategies are effective skills, methods or other conscious behaviors that learners adopt to optimize learning process, enhance language knowledge and memorize information knowledge. Generally, successful English learners have learning strategies that are appropriate for themselves. For different students, teachers should guide and train their learning strategies, enhance their consciousness of strategies and use effective strategies to promote their listening study.

College English teaching is a systematic project involving many factors. Teachers should not only impart language knowledge and skills but also teach students to master English learning strategies. Some researches show that the strategies that College English learners usually use are memory strategy, cognitive strategy and metacognitive strategy. Flavell says individuals' cognition of their own intellectual activities is metacognition, i.e., individuals' ability to learn their cognitive process and adjust these processes. Metacognitive strategy is a typical learning strategy, which refers to the strategy that students use to monitor and control the whole learning process effectively [5]. Oxford and Wen Qiufang combine with features of the process of listening comprehension and conclude a set of listening strategies, including metacognitive strategy, cognitive strategy, and social contact/ affective strategy. In detail, metacognitive strategy contains 6 sub-strategies, i.e., language consciousness, selective attention, practice in advance, self-management, self-monitoring and self-evaluation [6]. Metacognitive strategy is a management step that students use to learn foreign languages successfully, such as making plans, monitoring process and evaluating effect etc. How can we solve the problem that listening ability of students upgraded from junior colleges to universities is low? We should start with training and guiding students to master and apply learning strategies, combine strategy training guidance with practical classroom teaching and explore new methods. Strategy training should be a component of foreign language listening teaching and integrated with listening teaching. Via training, teachers make students improve their consciousness of learning strategies, increase range of their strategy selection, practice and cultivation their self-monitoring and self-regulation capability and improve their listening learning ability and performance ultimately. It is essential to carry out comprehensive training about students' listening learning strategies, fro which can make learning process more relaxing, more flexible, more convenient and more efficient.

\section{Application strategies}

a). It is essential to hold teacher-student forums regularly in batches. From the date of students' enrollment, teachers should educate students about learning objective in batches according to their English performance in entrance examination by which students may be upgraded from junior college to universities regularly to make them know significance of English learning for them and recognize that enhancement of foreign language teaching is a requirement of improvement in educational quality. As trainers of learning strategies, inspectors of strategy application, coaches showing students right ways and coordinators of learning process, teachers need learn problems existing in students' strategy application, help them establish learning objectives, arrange difficulty of listening training step by step, deploy learning tasks and then spend some time in inspecting implementation of plans in classroom.

b). It is necessary to attach importance to pronunciation and cultivate language sense. Encourage students to do natural practice (listening to English broadcast, songs and lectures and watching English films etc.). Improvement in listening ability is a long process. Classroom provides an effective listening training mode for students. Nevertheless, since the time in classroom is limited, it 
is difficult to achieve expected foals. Thus, students need do self-determination exercise after class. By intensive listening training about familiar English pronunciation, intonation (such as coherent reading, voiced sound, ring and falling tone and pause) and making students familiar with application of common vocabularies and patterns, students' sensitivity to listening in combination with context to acquire information rapidly and accurately can be improved.

c). Teachers should enlighten students to learn to use skills of listening comprehension, such as predict content of tapes by analyzing options and improve capability of predictive association by learning background materials; and master skills combining intensive listening with extensive listening. It is common that the whole situation is affected because students cannot comprehend a word or phrase when they practice listening. In addition to accumulation of idioms at ordinary times, extensive listening can help students understand input, which is a real good way. Extensive listening lay particular emphasis on quantity of exercise and acts as extension of intensive listening and an essential measure by which effect of listening can be guaranteed. Extensive listening accelerates the speed at which language learners accumulate knowledge and can improve auditory reaction capability and overall ability to comprehend discourses.

d). Teachers ought to supervise students to correct bad habits in the process of listening, for instance, students translate English into Chinese while they do English listening. In addition, train students to master methods like meditation and deep breath to overcome anxiety and fear, establish confidence, choose appropriate strategies under the state of intensive concentration and finish listening tasks.

e). Teachers may guide students to analyze their own features, choose appropriate materials for listening training, find listening train methods that are appropriate for them, evaluate their performance and progress objectively, carry out self-reflection consciously and persevere all the time. Content that is too difficult or too simple had better not be used as long-term materials for listening training. Emotional anxiety can be reduced and listening comprehension ability can be improved only when input language materials are comprehended by students. Content selection should have diversity, epochal character and interestingness simultaneously in order to arouse students' interest in study. Students should make phased adjustment according to demands of study to make themselves experience gains and sense of achievement in listening training each time.

\section{Conclusion}

Via one-year metacognitive training for improvement in listening ability of students upgraded from junior colleges to universities, the author deeply knows that his comprehension of theories about learning strategies is not deep enough, mastery about practical experience in training is insufficient and application of research methods is not skillful enough. Although this affect effectiveness of training to some extent, the author and students deem that combination between application of metacognitive strategy and classroom teaching can help students avoid inefficient study and achieve the effect that twofold results are got with half the effort. Metacognitive strategy can cultivate students' correct language learning beliefs and can be migrated and applied to other kinds of English study to improve overall level of English.

\section{References}

[1] Liu Runqing and Dai Manchun: A Research on Current Situations and Development Strategies of Foreign Language Teaching at Chinese Colleges. Foreign Language Teaching and Research Press, 2004,6

[2] Liu Dan: College English Teaching Reform for Students Upgraded from Junior Colleges to universities. The Border Economy and Culture, 2009,5.

[3] Wen Qiufang: Changing Laws and Features of English Learners' Learning Motivation, Beliefs and Strategies. Foreign Language Teaching and Research, 2001,2. 